\title{
Men and Masculinity in Men's Stylish Lifestyle Magazine
}

\author{
Collin Jerome \\ Centre for Language Studies, Universiti Malaysia Sarawak, 94300 Kota \\ Samarahan, Sarawak, Malaysia \\ e-mail: jcollin@cls.unimas.my; C.Jerome@sussex.ac.uk
}

\begin{abstract}
This paper discusses qualitative findings from a series of focus group discussions with six adult Malaysian men, aged 24-34, on the representation of men and masculinity in Men's Folio, a stylish lifestyle men's magazine. It highlights the extent to which the language used in the magazine's editorial content and advertisements that feature musculature images, fashion and style, and feminized grooming products and practices that have diversed impacts on the respondents' notions of a modern male identity.
\end{abstract}

Key words: men's lifestyle magazine, masculinity, masculine identity

Men's magazines today have become sites of significant inquiry that offer alternative views on the representation and construction of the modern male identity. This is especially evident in the growth of men's lifestyle magazines that are believed to be sites for men to learn how to become a man in this post-traditional modern world (Gauntlett, 2002; Jackson, Stevenson, \& Brooks, 2001; Mckay, Mikosza, \& Hutchins, 2005).The emergence of new men's lifestyle magazines such as 'New Man' and 'New Lad' cover varied aspects of men's lives that were "once considered strictly female" (Beam, 1996). This is clearly evident in the increasing number of men's magazines that range from the upscale and literary (Esquire and $G Q$ ) to practical, and outdoorsy (Men's Health, Men's Fitness, Verge, Men's Journal) to hip and girl-crazy (Details, Maxim, Men's Perspective) (Beam, 1996). The fact that "men don't read magazines, except for sports or hobby titles" (Braithwaite, 2003, p. 115) and that men's magazines are only restricted or limited to sports or hobbies may no longer be relevant. Jackson, Stevenson, \& Brooks (2001) posits that new men's magazines "have encouraged men to "open up" previously repressed aspects of their masculinity and how "the magazines signify the 
potential for new forms of masculinity to emerge even as [they] are simultaneously rein scribing older and more repressive forms of masculinity" (Gauntlett, 2002, p. 170). In the case of Malaysia, the publications of new men's magazines can be traced in the English language edition of Rodale Men's Health Malaysia, Men's Folio and New Man, the Chinese language men's magazine Men's Uno, and the Malay language Maskulin, Umph! and GLAM Lelaki (GLAM for Men). But previous studies that explore what these magazines say about the modern male identity and the impact that it has on Malaysian male readers' notions of their masculinity and masculine identity are almost absent.

One possible explanation for this is the fact that there is a lack of concrete empirical and ethnographical studies on the construction of gender and sexuality in Malaysia. Gender and sexuality are largely defined in terms of cultural and religious influences and practices. With an eminently strong presence of male dominance and feminine subordination, gender and sexuality are often subject to "the normative definitions of "right" and "wrong" within "its almost hidden and unspoken relation of power" " (Shamsul \& Fauzi, 2006, pp. 68-69). Shamsul and Fauzi (2006) argue that Malaysia is

... a multi-ethnic postcolonial society in which the conception of sexuality and gender becomes heterogenized and automized into ethnic enclaves, which, in turn, invite contestation articulated, for instance, in religious terms. With the co-existence of the practice and enforcement of the modern constitution alongside religious laws, the individual and particular ethnic group experience different forms of external control and internal form of moral-self-control in relation to sexuality and gender. (p. 62)

In this country, discussions on gender and sexuality are often tolerated from a distance and little is known in regard to how men and women form their masculine/feminine identities, which sites and resources they may have referred to in doing so. Sexuality and sexual-related matters, especially in the context of the Malay(sian) culture, are usually not discussed in the public but "expressed only in a limited close circle of intimate relatives and friends, and usually in a teasing or tongue-in-cheek manner" (Shamsul \& Fauzi, 2006, p. 69). Yet the increase in social problems such as rape, incest, adultery, and sexual harassment tell a 
different story in term of how present-day Malaysians response to matters concerning sexuality in their daily lives. Many of them use various mediums to express divergent notions of gender and sexual identity, for instance, through the cyberspace. This medium is used to challenge the "external control" and "internal form of moral-self-control" as well as "the normative definitions of "right" and "wrong" relating to gender and sexuality. Traditional notions and values of gender and sexuality are replaced by new ideas that are transmitted through globalised communication.

It is in this regard that Malaysian men (and women) may have constructed their own visions of a modern gendered and sexualized identity and how magazines may help articulate these visions. Gauntlett (2002) posits that there are varied ways of becoming a man in this post-traditional modern world and that "social definitions of masculinity may be ignored, negotiated, or resisted by some viewers (in this case readers) and not others" as "different strategies of representational practice may articulate in different ways to historically specific 'subject' positions, social identities, or social formations" (Hanke, 1992, p. 127). To prove this, the paper discusses how six adult Malaysian men respond to the representation of masculinity and male identity in Men's Folio magazine. The focus group discussion was used to gather the respondents' views on the kind of masculinity that the magazine exemplifies through language used in the editorial contents and advertisements. In addition, the respondents' definitions of masculinity were also documented and analyzed. Their views may provide valuable insights into the effects on how men's magazines have on male readers' notions of masculinity. The study on this issue may extend the research on the representation of men and masculinity in men's magazines that seem to be lacking especially in the non-western context (Taga, 2005).

\section{Studies on Representation of Men and Masculinity in Men's Magazines}

Studies on the representation of men and masculinity in men's magazines are mostly derived from the West. They examine the magazines' diverse focuses and interests within the content analysis framework (Fejes, 2003). Other aspects that these studies look at are the language used in the editorial content and advertisements, the masculine 
images that the magazines feature and how these affect the target readers or audience. White and Gillet (1994) found out that young male readers have keen interest in body-building culture in men's health magazines (Vigorito \& Curry, 1998). Lifestyle magazines such as GQ, Esquire, Arena, and For Him were found to promote a "primarily consumerist-defined masculinity" (Collier, 1993). In other related studies, magazines for younger men, aged 18-24, focused more on youth-related activities, and magazines for older men focused on careers and workplace and thus reinforced traditional masculine identity through the portrayal of men's occupational roles (Willemson, 1988).

The language used in the editorial content and advertisements in men's magazines, for instance, was found to construct and represent specific types of masculine identity. To further illustrate this point, a study on language used and gender representation in girls' and boys' magazines revealed that more emotive words were used in girls' and cool, tough words and expressions, as well as long sentences with complex structures were in boy's magazines (Willemson, 1998). Language used in men's and women's magazines, on the other hand, reveals clear evidence of gendered differences. Mullac and Lendell (1994) found out that there were more judgmental adjectives in men's magazines as opposed to adjectives, intensifying verbs, emotive words and longer sentences in women's magazines (Willemson, 1998), suggesting an evidence of differences in the use of gendered language. One explanation for this is that most female authors in women's magazines and male authors in men's, as Maynard (1995) claimed, were expected to use gendered language as the means for addressivity, 'talking' to or 'addressing' gendered readers. It can be said that men's and women's magazines play a significant role in articulating the types of masculine and feminine identity and impart them to target (and non-target) readers by means of addressivity, most importantly through the language that the magazine vis-à-vis editors and writers use. Yet how much do we know about the readers' own response, reply or reaction to the masculine or feminine identity that these magazines represent? What effects does the language used, for instance, in the editorial content and advertisement have on readers' response to the magazine's portrayal of men and women? How do their responses reflect their personal notions of masculinity and femininity? These are some of the questions that the paper seeks to address by looking at Malaysian readers' view on the representation of the modern male identity in Men's Folio magazine. 
It can also be said that the findings in this paper, although inadequate and exclusive to a specific group of male respondents (i.e. Malaysians), help to contribute to the body of work and research that explore the effects of magazine's representations of men and masculinity on male readers. It may also contribute to the present lack of evidence on the findings based on actual responses on media's (which may also include magazines, television, and so on) messages about men and masculinity (Giles, 2003). Fejes (1992) proffers that there should be more 'effects' studies on 'how audiences, particularly adult male audiences, use these images [of men and masculinity in the media] in the construction and maintenance of their own masculinity" (pp. 19, 22). In addition, this paper also promotes the notion of constructing gender identity through literacy. Studies have shown that literacy practices help readers construct their gender identity. Readers develop their gender identities through the interactions with texts, a process called "doing gender" (West \& Zimmerman, 1987) by either relying on their stereotyped (gender schematic) or non-stereotyped (gender aschematic) beliefs about masculinity and femininity. But such process may differ from one gender to the other or from one man to the other man, depending on several factors such as race, class, culture and "gendered histories", which may affect the way a man and a woman read the texts and then define their gender identity (Gilbert, 1993). This is another aspect that this paper looks at in terms of how the respondents who come from different ethnic groups and different cultural backgrounds respond to the representation of men and masculinity in Men's Folio magazine.

\section{METHOD}

\section{Respondents}

Six adult male respondents, aged 24-34, were selected using "purposeful sampling" method which lies in "selecting information-rich cases from which one can learn a great deal about issues of central importance of the study in depth" (Patton, 1990, p. 52). In a survey prior to collecting the data, the respondents were identified as regular readers of men's lifestyle magazines such as the Malaysian edition of Men's Health and FHM, and locally published New Man as well as Men's Folio magazine. Two were final year university students, one was unemployed and searching for employment, one was self-employed, and the remaining 
two worked for companies. They were well educated, all having received tertiary education. All were from the city and regular readers of men's lifestyles magazines that included Men's Folio. Additionally, they viewed these magazines as sites for discourses of masculinity, for instance, their tendency to emulate the magazines' fashion sense.

\section{Texts}

Men's Folio magazine was mainly used for the research for the following reasons: (1) it is a popular stylish lifestyle magazine that covers issues relating to men's fashion, style and design; and (2) it is deemed as a possible site for the formation of the modern male identity in Malaysia. As "a stylish lifestyle magazine for sophisticated gents" (Lonely Planet, 2007) the publisher, Eddy Koh claimed that the magazine was a proof that "Malaysian men were becoming more fashion- and style-savvy" and that they were "keen to know what's the hottest and latest fashion, style and design trends" (Khoo, 2006). He added that "the magazine is dedicated to fashion, style and design while exhibiting an appreciation for the finer things in life. It's about catering to a lifestyle that encompasses travel, dining and what was traditionally considered women's territory - the home"

The respondents were given a selection of Men's Folio magazines that were published (bi-monthly) between 2003 and 2005. Only three issues were selected from each individual year: beginning, middle and end of year issues: January - February, May - June, November - December $2003(n=$ 3); January - February, May - June, November - December $2004(n=3)$; and January - February, May - June, November - December $2005(n=3)$. The selection was made on the basis that there were no significant changes in the editorial content and patterns of advertisements throughout the years, covering the latest updates on men's fashion and style.

\section{Procedures}

Two main procedures were involved: (1) reading tasks; and (2) focus group discussions. The respondents were divided into two groups for the reading task; the first group was given three selected issues from 2003 with the first respondent going through each of these issues within two working days before passing them on to the second respondent (and later the third). 
The second group carried out similar task concurrently with issues from 2004. This took about a week to complete before the first group read the 2004 issues while the second group, 2003. The first group later spent another week to read the 2005 issues before passing them on to second group in the succeeding week. Throughout the task, the participants were required to go through the editorial content (e.g. articles) and advertisements by focusing on the language use (e.g. linguistic features). However, they were not told to focus or reflect on masculinity as this would restrict their readings and conveniently point to the categories or themes that the researcher was interested in looking at. They were asked to write down short notes at any point during the reading task, to record any aspect that might struck them as interesting, disturbing or confusing. What followed next was a series of group discussions. In the first discussion, all six respondents were asked to define what masculinity meant to them and this took about nearly 1 hour and 25 minutes. The second discussion, which lasted for nearly two hours, give the respondents sufficient time to comment on the messages and ideas about men and masculinity that the magazine aimed to portray and how the language used in the editorial content and advertisement achieved this, and whether the magazine reflected their notions of masculinity. The discussions were audio taped and then transcribed verbatim.

\section{Data Analysis}

The data was collected and analyzed using focus group discussion method. Giles (2003) posits that the data from focus group discussion is analyzed "from an interpretative perspective [to] examine the different meanings that different media products hold for people" (p. 39). The method "generate [s] a meaningful discussion" with six to ten participants so that "individual contributors [do not] drop out of the conversation" (p. 39). Furthermore, the method documents comments and patterns and data collection would, according to Livingstone and Lunt as cited in Giles (2003), cease "when comments and patterns began to repeat and little new materials was generated" (p. 29).

Different levels of data analysis were undertaken to determine significant patterns and themes from the respondents' views. In regard to their definitions of masculinity, the 'traditional-biological' and 'openborderless' themes were identified, informing the formation of male 
masculinity that on one hand sustained the traditional hegemonic masculinity and on the other wholly rejected it. These themes were further analyzed in terms of gender schema theory by highlighting the evidence of gender schematic and aschematic construction of masculinity. The 'new/modern male' was identified as possessing the type of masculinity that the magazine aimed to portray and it was further described around the themes of 'fashionable and stylish men', 'male professionals', 'male appearance' and 'male beautification'. Finally, the respondents' views on the language used in the editorial content and advertisement and how it conveyed the modern male identity were analyzed according to the identified themes of 'descriptive language', 'visual depiction (as another form of language)' and 'persuasive language'. Their views on whether the magazine reflected their notions of masculinity were also documented and discussed. The following is the framework that the researcher designed with to analyze the data from focus group discussion.

\section{Respondents' definitions of masculinity}

a. 'Traditional-biological'

b. 'Open-borderless'

2. Respondents' views on the type of masculinity Men's Folio represents 'New/Modern' male identity

a. Fashionable and stylish men

b. Male professional

c. Male appearance

d. Male beautification

3. Respondents' views on language use in Men's Folio that represent men and masculinity
a. Descriptive language
b. Visual depiction
c. Persuasive language

\section{Figure 1. Framework for Analysis}

\section{FINDINGS AND DISCUSSION}

The results are presented in the following headings: (1) Views on Masculinity; (2) The New/Modern Male; and (3) Language Used: Descriptive, Visual and Persuasive. 


\section{Views on Masculinity}

There were two major camps in regard to the respondents' definitions of masculinity. Most of the respondents defined it in terms of male traditional attributes (e.g. confidence) and appearance (e.g. manly appearance and physical well-being). One respondent claimed that "masculinity is being biologically male regardless of his attributes or roles" while others believed that it referred to "qualities" such as "strength, confidence, self-respect, independent [sic]" to distinguish himself from female qualities, highlighting an evidence of a rather stereotypical, gender schematic definition and understanding of masculinity.

It was evident that some respondents moved away from being bound up by traditional, if not stereotypical views on masculinity. One respondent claimed that he was at ease with his 'carefree' attitude and could not be bothered by the way he presented himself, but went on saying that he would want to be "comfortable", "independent", "easy-going" and "responsible". Another respondent clearly felt that it was "a borderless" gender category:

Previously, it would be the tough, macho, unmoving personality of the male figure. Now, in the last few years, even female can be masculine. Look at female body builders ... So it's [masculinity] definitely broader in definition. Not to mention how tough or how big your body is, doesn't really fit anymore.

It was also interesting to find out that the magazine became the source of masculinity for one respondent who felt that it was a "melting pot" that mixed the Western and Eastern masculinities. He looked up to both popular Asian (Japanese actors, Kimura Takuya and Soremachi Takeshi) and Western (Johnny Deep, Keanu Reeves, and Jude Law) male actors, who are famous for their eccentricities and peculiarities but still remain masculine, implicating a media-saturated definition of masculinity.

\section{The New/Modern Male}

The respondents agreed that the magazine portrayed the images of new or modern male identity. Yet the magazine's portrayal or representation did not really reflect their personal notions of what masculinity and the modern 
male identity meant for them. They felt that they could not achieve the ideals or standards set, implicating that the magazine's notion of modern male identity was too masculinised, beautiful and lavish. While some respondents claimed that the magazine did not reflect how they defined masculinity, others looked at it as a site that shaped and formed their masculine identity. As anticipated, they claimed that the magazine, a "stylish lifestyle magazine for sophisticated gents" portrayed the images of "stylish" and "fashionable" men and suggested that it was indeed a site for the formation of the new or modern male identity. The respondents agreed that these stylish and fashionable men were depicted in their traditional masculine attributes in terms of how they were contextualized in the work environment. One respondent explained that men were portrayed as "wealthy", "daring", "risk taker[s]", "career minded" in their roles as "young professional[s]" and "executives."

... stylish and fashionable. Constant highlights of fashion and accessories (watch) that seem to be associated with modern man ...daring and risk takers. Dare to be different from or at least on par with their counterparts - woman ... wealthy, of a stable employment. Rich dad, rich son, the magazine shows a lot of in-person stories of the elite managers as well as celebrities, not to mention all the expensive stuff.

Fascination over male images was evident in the men's responses to the magazine that is known for covering issues relating to fashion and style. One participant observed that the male images were "handsome' and "sexually appealing", "muscular", "athletic", and "strong". The respondents came to a general consensus that these were the modern male ideals that they believed could not be easily attained or achieved. At least one respondent felt that the image of the new/modern male was represented through male "beautification" with the magazine's emphasis on "fashion, [beauty] products and accessories." While he felt that the magazine portrayed the kind of masculinity that he embraced, he could not possibly afford the expensive lifestyle.

\section{Masculinity and Language Used}

The respondents agreed the language used helped the magazine to convey ideas and messages about the new/modern male identity. Almost 
all respondents claimed that a descriptive language was used mostly through the adjectives that not only associated men with fashion and styles but also sustained, demonstrated and appropriated manliness for example "bold(ness)", "daring", "outstanding" and those that relate to men's careers such as "gorgeous suits" and "state-of-the-art creations."

While specific words were used to describe male professionals such as "designer" and "CEO", language use in the editorial content and advertisement further reinforced successful and confident images of the modern male. One respondent commented that the magazine captured the essence of the "sophisticated gents":

... the career minded, young executives, professionals and appearance conscious. It shows that the magazine wishes to portray the images of a new or modern man. Apart from that the language also represents the distinguished and sophisticated man, especially in the articles written about $\mathrm{CEO}$ and corporate male figures.

Additionally, the description, as one of the men pointed out, was believed to be a generic structure for the articles, a technique that could have been employed by the writers to reinforce masculine identity. He added that the description came first (e.g. headlines) before the proper article. While most of the respondents focused on the use of specific words such as adjectives and noun phrases, one respondent clearly felt that visual depiction of male models (mostly white Caucasian and Pan-Asian males) was a kind of language that not only produced a mental image but also revealed and further reinforced the identity of the modern male:

Pictures tell a thousand words, that means it is considered as a language of its own ... the pictures in the magazine describe a lot on men's importance of appearance, career as well as attributes ... sexually appealing, handsome man, muscular, athletic and strong

The language used was not entirely descriptive as one respondent noted. To him it was more persuasive as he felt 'persuaded' to read what the articles were about. He claimed that the writers of the magazine articles had a way in "weaving each word in a seamless way" which was "suitable and custom made for the type of article being written, for example, technical language used in articles on watches." This dispels the myth that men do 
not really read or care about what they read in magazines, which confirms Maynard's (1995) view on "addressivity" where writers in Men's Folio who are men employed gendered (masculine) language in addressing target readers.

The findings revealed that the respondents have diverse notions on what it means to be a man. Some of them claim that masculinity is not and should not be a rigid or fixed gender category, suggesting not only a contrast between a gender schematic (e.g. traditional-biological) and aschematic (e.g. open-borderless and media-saturated) definition of masculinity, but also the respondents' personal notions of what it means to be a man based on individual lived experiences of being a man. This is congruent to van Zoonen's (1998) view that "unstable character of gender and the continuous negotiation taking place in and with media texts may suggest that it is a volatile, almost meaningless category to be filled with meaning according to individual preferences, social conditions, cultural peculiarities, or historical contingencies" (pp. 326-327). Additionally, the respondents' varied definitions of masculinity are in line with Kimmel, Hearn, \& Connell's (2005) view that men and masculinities are "socially constructed, produced and reproduced" and that men are seen as "variable and changing across time (history) and space (culture), within societies" (p. 3 ). It is important to note that although the magazine captures the essence of the modern male, the respondents acknowledge that the ideals or standards set are too high and unattainable.

The fact that men's lifestyle magazines, as Gauntlett (2002) posits, are still a relatively new phenomenon, they are in fact a significant site for the formation of the modern male identity, covering every aspect of men's lives today. This is in line with Men's Folio's aims to cover "fashion, style and design while exhibiting an appreciation for the finer things in life... a lifestyle [for men] that encompasses travel, dining and what was traditionally considered women's territory - the home" (Khoo, 2006). Yet the respondents cannot afford such lifestyles. This may be due to their level of income where half of the respondents are unemployed. Moreover, the respondents who confess their "fascination" over images of "beautiful" and "sexually appealing" male models require further studies, as it questions how men view or gaze at other men; an act that is still considered to be unmanly albeit the changes in attitudes towards men gazing at other men in the modern Malaysian society. 
It is important to note that the magazine writers use descriptive adjectives and other phrases that are normally found in women's magazines but repressed in men's magazines for fear of unmanly or feminine associations. This is in contrast to Mulac and Lendell's findings on the frequent use of judgmental adjectives in men's magazines (Willemson, 1998). It is, however, a question of magazine genre, purposes and target audience. These adjectives (e.g. Sassy) are clearly acknowledged by the respondents, yet, these adjectives do not soften the masculine aspect as the writers of the magazine articles cleverly weave masculine and feminine qualities without endangering the former by describing and maintaining men's traditional attributes (e.g. successful entrepreneurs and famous designers, famous and rich personalities). This encapsulates Hanke's (1992) view that "the key question is not whether such a version of masculinity is more modern or less (hetero)sexist than traditional...but how masculinity is defined and re-defined in order to remain hegemonic" (p. 196). Further investigations may provide more insights into how men's notions of masculinity are influenced by feminine language that is used in stylish lifestyle magazines for men.

The findings also suggest that the magazine portrays the new or modern male identity through descriptive and persuasive language, and visual male images in the editorial content and advertisement, which are clearly in line with the publisher's aim to create a lifestyle magazine for "stylish" and "sophisticated" men in Malaysia. Although the respondents agree that the magazines are successful in representing the new or modern male identity, they argue that they cannot achieve or attain the ideals or standard sets. It can be said that they have their own visions of a modern man where the ideals or standards would either be within their reach or to be based on their own principles. This may suggest a kind of mismatch between the magazine's notions of masculinity and the respondents' own. It confirms Cantor's (1990) argument on how gender may vary according to genre and the audience (p. 191). Moreover, it is clearly felt that the language used, confines other aspects of masculinity apart from fashion and style; another evidence of a mismatch between the magazine and the men's notions of masculinity. On the other hand, the respondents' urge for representations of other forms of masculinities in contrast to Men's Folio's over representation of the perfect male images explains the need to investigate the representations of other forms of masculinities in different 
genres of men's magazines, all of which are responsible in shaping gender identity (Renzetti \& Curran, 1995).

\section{CONCLUSION}

It can be concluded that this paper provides an insight into the study on men and masculinity in relation to men's views on men's lifestyle magazines as significant sites for the formation of the modern male identity. Although the views are drawn from a small sample of Malaysian men, it can be said that their varied definitions of masculinity may point to how men from this country define what it means to be man in a modern world. As a stylish lifestyle magazine, Men's Folio captures the essence of the modern male identity by encapsulating and bridging modernity and masculinity. On the other hand, male hegemonic masculinity is sustained and reinforced through a variety of representational strategies employed by the magazine writers, which include previously, if not traditionally repressed areas of masculinity such as beauty and fashion. Yet this is executed and deliberated without endangering masculine qualities. It is hoped that more studies would be conducted to explore media-mediated masculinity and its varied implications on the notions of men and masculinity in the modern world.

\section{REFERENCES}

Beam, C. (1996). It's a guy thing - Broader coverage by men's magazines. Retrieved May 6, 2005, from http://www.findarticles.com/p/articles/ mi_m3065/s_n2_v25/ai_17944699

Braithwaite, B. (2002). Magazines: The bulging bookstalls. In A. Briggs, \& P. Cobley (Eds.), The media: An introduction (pp. 104-120). Essex: Pearson Education.

Collier, R. (1993). The new man: Fact or fad? Retrieved May 6, 2005, from http://www.achillesheel.freeuk.com/article14_9.html.

Fejes, F. J. (1992). Masculinity as fact: A review of empirical mass communication research on masculinity. In S. Craig (Ed.), Men, masculinity and the media (pp. 9-22). United States of America: Sage Publications.

Gauntlett, D. (2002). Media, gender and identity: An introduction. London: Routledge. 
Gilbert, P. (1993). (Sub)versions: Using sexist language practices to explore critical literacy. Australian Journal of Language and Literacy. 16(4), 323-32.

Giles, D. (2003). Media psychology. Mahwah, New Jersey: Lawrence Erlbaum Associates.

Hanke, R. (1992). Redesigning men: Hegemonic masculinity in transition. In S. Craig (Ed.), Men, masculinity and the media (pp. 185 -198). United States of America: Sage Publications.

Jackson, P., Stevenson, N., \& Brooks, K. (2001). Making sense of men's magazines. Polity Press: Cambridge.

Khoo, R. (2006, September). Refined lad's mags. The Star. Retrieved September 30, 2006, from http://thestar.com.my/lifestyle/story.asp?file=/2006/9/5/ lifeliving $/ 15015884 \&$ sec $=$ lifeliving

Kimmel, M. S., Hearn, J., \& Connell, R. W. (Eds.). (2005). Handbook of studies on men and masculinities. United States of America: Sage Publications.

Livingstone, S. (2003). Making sense of television: The psychology of audience interpretation. In D. Giles (Ed.), Media psychology. Mahwah, New Jersey: Lawrence Erlbaum Associates.

Lonely Planet (2007). Retrieved January 20, 2007 from www.loneyplanet.com/ worldguide/destination/asia/singapore/essential? $\mathrm{a}=$ media

Maynard, M. L. (1995). Interpretation and identification of gendered selves: Analyzing gender-specific addressivity in Japanese advertising text. Language and Communication, 15, 149-163.

Mckay, J., Mikosza, J., \& Hutchins, B. (2005). Gentleman, the lunchbox has landed: Representations of masculinities and men's bodies in the popular media. In M. S. Kimmel, J. Hearn, \& R.W. Connell (Eds.), Handbook of studies on men and masculinities (pp. 270-288). United States of America: Sage Publications.

Meijer, I. C., \& van Zoonen, L. (2002). From Britney Spears to Erasmus: women, men and representation. In A. Briggs, \& P. Cobley (Eds.), The media: An introduction. Essex: Pearson Education.

Mullac, A. \& Lundell, T. L. (1994). Effects of gender-linked language differences in adults written discourse: Multivariate texts of language effects. Language and Communication, 14, 299-309.

Patton, M. P. (1990). Qualitative evaluation and research methods: A systematic approach. London: Sage. 
Renzetti, C. M., \& Curran, D. J. (1989). Women, men and society. United States of America: Ally \& Bacon.

Shamsul, A. B., \& Fauzi, M. (2006). Making sense of Malay sexuality: An exploration. Sari, 24, 59-72.

Taga, F. (2005). East Asian masculinities. In M. S. Kimmel, J. Hearn, \& R. W. Connell (Eds.), Handbook of studies on men and masculinities (pp.129140). United States of America: Sage Publications.

Vigorito, A. J. and Curry, T. J. (1998). Marketing masculinity: Gender identity and popular magazines. Retrieved February 12, 2005, from http://www. findarticles.com/p/articles/mi_m2294/is_n1-2_v39/ai_21136466

West, C., \& Zimmerman, D. H. (2000). Doing gender. In M. S. Kimmel (Ed.), The gendered society reader (pp. 131 - 149). New York and Oxford: Oxford University Press.

White, \& Gillet (1994). In A. J. Vigorito, \& T. J. Curry. Marketing masculinity: Gender identity and popular magazines. Retrieved February 12, 2005, from http://www.findarticles.com/p/articles/mi_m2294/is_n1_v39/ai_21136466

Willemson, T. M. (1988). Widening the gender gap: Teenage magazines for girls and boys. Retrieved February 12, 2005, from http://www.findarticles. com/p/articles/mi_m2294/is_n9-10_v38/ai_20914094

Zoonen, L. V. (1995). Gender, representation, and the media. In J. Downing, A. Mohamadi, \& A. Sreberny-Mohamadi (Eds.), Questioning the media: A critical introduction (pp. 311-328). CA: Sage. 